\title{
CORRESPONDÊNCIAS EURO-AMERICANAS: POE, BAUDELAIRE, VALÉRY, WILSON E A CONSTRUÇÃO DO SIMBOLISMO
}

\section{EURO-AMERICAN CORRESPONDENCE: POE, BAUDELAIRE, VALÉRY, WILSON AND THE CONSTRUCTION OF SYMBOLISM}

\section{Anelito Pereira de Oliveira ${ }^{1}$}

RESUMO: Este artigo revisita um dos temas complexos da história literária ocidental, que é a construção da poética simbolista no século XIX, passo decisivo na instauração da modernidade. Detém-se, para tanto, na relação entre Edgar Alan Poe e Charles Baudelaire, responsável, com traduções pioneiras, pela apresentação do autor estadunidense ao mundo letrado francês. A abordagem é estimulada pela interpretação que Paul Valéry faz da relação entre os dois autores, bem como pela interpretação que Edmund Wilson apresenta do quadro literário romântico anglo-saxão. O Simbolismo, à luz das reflexões desses autores, seria resultante de uma ação supra-nacional, de uma política de poetas, que teve como fim superar limitações sociais e cultuais de países específicos, de estados-nação.

PALAVRAS-CHAVE: Simbolismo. Edgar Allan Poe. Charles Baudelaire.

\begin{abstract}
This article revisits a complex theme in Western literary history, the construction of symbolist poetics in the nineteenth century, which was a decisive step towards establishing modernity. To this end, the relationship between Edgar Alan Poe and Charles Baudelaire who, with his pioneering translations, presented the American author to the French literary world. The approach is stimulated by Paul Valéry's interpretation of the authors' relationship, as well as by Edmund Wilson's interpretation of the Anglo-Saxon
\end{abstract}

\footnotetext{
${ }^{1}$ Doutor em Literatura Brasileira (2006) pela Universidade de São Paulo. Mestre em Literatura Brasileira (1998) pela Universidade Federal de Minas Gerais. Graduado em Letras (1995) pela mesma universidade. São Paulo, São Paulo, Brasil. E-mail: anelitodeoliveira@globomail.com
} 
romantic literary framework. Symbolism, in the light of these authors' reflections, would be the result of a supranational action, a policy of poets, whose purpose was to overcome the social and cultural limitations of specific countries, of nation-states.

KEYWORDS: Symbolism. Edgar Allan Poe. Charles Baudelaire. 
O estadunidense Edgar Allan Poe, sem ser rigorosamente um autor simbolista, teve papel decisivo no processo de constituição do Simbolismo francês, fonte literária dos demais Simbolismos, notadamente o brasileiro, que tem em Cruz e Sousa, leitor-intercessor audacioso do autor de poemas emblemáticos da modernidade, como "The raven" (1845), sua maior referência, conforme já apontei (Oliveira, 2011, p. 164-171). Charles Baudelaire, que teria lido Poe pela primeira vez em 1847 e experimentado, segundo Edmund Wilson (1987, p. 16-21), uma "estranha comoção", foi o responsável, com suas traduções do inglês ao francês, por sua disseminação no cenário europeu.

Os textos de Poe eram, para o "romântico tardio" de Les fleurs du mal (1857), como o considera o ensaísta de Axel's castel (1931), algo que ele mesmo desejara escrever, em que havia "pensado vaga e confusamente". Baudelaire "recebe" Poe de um modo afim do que, na década de 1840, ainda nem se cogitava, claro, como Simbolismo, que só se afirmaria, categoricamente, no final do século XIX, com poetas como Stéphane Mallarmé, Paul Verlaine e Arthur Rimbaud. Deve-se a Baudelaire a própria localização de Poe num mais-além não só do Romantismo então ainda em evidência, mas também do Realismo emergente e sua extensão lírica em alguns países, como o Brasil, que foi o Parnasianismo.

A recepção para-Simbolista de Poe por Baudelaire, como a podemos considerar, é o que Paul Valéry enuncia, de modo bastante fértil para a compreensão da problemática transtemporal inerente ao Simbolismo, no seu célebre ensaio "Situation de Baudelaire", incluso nas Variétés, obra originalmente 
editada em cinco volumes pela Gallimard no período de 1924 a 1945. Num dado momento de sua reflexão, diz Valéry, conforme a tradução brasileira de Maiza Martins de Siqueira em edição organizada por João Alexandre Barbosa:

Até Edgar Poe, o problema da literatura nunca havia sido examinado em suas premissas, reduzido a um problema de psicologia, abordado através de uma análise em que a lógica e a mecânica dos efeitos fossem deliberadamente empregadas. Pela primeira vez, as relações entre a obra e o leitor eram elucidadas e dadas como os fundamentos positivos da arte. (VALÉRY, 1991, p. 26)

Em Poe se encontra, portanto, uma atitude anti-romântica, que seria plenamente compreensível em face do Simbolismo, caso o Romantismo não fosse marcado também por um mal-estar na modernidade, de que resulta uma adesão à subjetividade em detrimento da objetividade. Explicação que tem valor, evidentemente, para fins mais didáticos: na prática, nem todo Romantismo é subjetividade nem toda sociedade moderna é objetividade. Romântico, Poe corresponde diferentemente a uma realidade diferente daquela cultivada pelo Romantismo em geral. Preparando esta compreensão de um Poe anti-romântico, diz Valéry, num outro ponto de sua reflexão:

Em uma época em que a ciência ia se desenvolver extraordinariamente, o romantismo manifestava um estado de espírito anticientífico. A paixão e a inspiração se persuadem de que só precisam de si mesmas. Mas, sob um céu totalmente diferente, no meio de um povo muito ocupado com seu desenvolvimento material, ainda indiferente em relação ao passado, organizando seu futuro e deixando às exigências de qualquer natureza a mais completa liberdade, aproximadamente na mesma época, um homem encontrou-se por considerar as coisas do espírito e, entre elas, a produção literária, com uma nitidez, uma sagacidade e uma lucidez nunca encontradas em uma cabeça dotada com a invenção poética. (VALÉRY, 1991, p. 26)

Esse homem é Poe, diferente em face do agora diferente, diferente dos românticos franceses, de Alphonse de Lamartine, Victor Hugo, Alfred de Musset, Alfred de Vigny, que representavam, por volta de 1840, um padrão de grande poeta, não só de poeta, de tal maneira que, para Valéry, o problema de Baudelaire se colocava em termos de um impasse: ser um grande poeta, mas não ser um poeta como esses estabelecidos como grandes na poesia francesa naquele momento. Todavia, a situação de Poe, visado a partir de uma imparcialidade que o juízo do pós-Simbolista Paul Valéry realmente não poderia portar, não era exatamente a mesma de Baudelaire, pelo fato mesmo de o estadunidense estar situado num outro cenário sociocultural. Não era, no fundo, o que se poderia entender apenas por uma situação de Poe, como se depreende a partir de Edmund 
Wilson em reflexão constante do seu Axel's Castle mencionado, que há muito também tem sua excelente tradução brasileira executada por José Paulo Paes. Diz Wilson:

De modo geral, era verdade que, em meados do século, os escritores românticos nos Estados Unidos - Poe, Hawthorne, Melville, Whitman e mesmo Emerson - estavam, por razões que seria interessante determinar, progredindo na direção do Simbolismo, e um dos acontecimentos de primordial importância no início da História do Movimento Simbolista foi a descoberta de Poe por Baudelaire. (WILSON, 1987, p. 16)

Poe para-Simbolista resulta da percepção de Baudelaire, o que constitui uma das cenas mais instigantes de estética da recepção na modernidade, colocando-nos na iminência de interrogações como: o que é Poe e o que é Baudelaire na imagem de ambos, amálgama de enunciado e enunciação, fixada pela historiografia e crítica literárias? Qual é o lugar que relações internas de sentido, intratextuais, ocupa na conformação da exterioridade da literatura, essa exterioridade, especialmente, a que nos remetem rótulos como Simbolismo? Ainda de acordo com Wilson, não foi tão fácil, dentro da literatura de língua inglesa, o entendimento da importância de Poe para o Simbolismo francês:

Para o leitor contemporâneo de língua inglesa, a influência de Poe pode ser difícil de entender: mesmo quando tal leitor se detenha a examinar as produções do Simbolismo francês, poderá surpreendê-lo que tenham causado pasmo. A miscelânea de imagens; as metáforas deliberadamente mescladas; a combinação de paixão e agudeza, de maneiras prosaicas e solenes; o amálgama audaz do material com o espiritual - tudo isto pode parecer-lhe muito respeitável e familiar. Ele sempre o conheceu na poesia inglesa dos séculos XVI e XVII: Shakespeare e os autores isabelinos praticaram todas essas coisas sem teorizar a respeito delas. Pois não é esta a linguagem natural da poesia? Pois não é a norma contra a qual, na literatura inglesa, o século XVIII constituiu uma heresia e à qual os românticos fizeram o possível para regressar? (WILSON, 1987, p. 18).

Regressando a Valéry, o Poe de Baudelaire se distingue por um esforço de racionalização do fazer poético-literário que não se encontra nos românticos. Essa racionalização tem consequência de vária ordem, a começar pela alteração da relação entre obra e leitor, que passa a ser determinante na atividade do escritor, do poeta. A ênfase que Valéry dá a essa questão acaba por abrir à nossa frente um caminho muito claro para o acesso ao Simbolismo como estética do impossível, para a compreensão da razão da sua inadequação aos parâmetros de inteligibilidade consagrados pela prática da literatura ao longo da história ocidental, parâmetros inscritos, pode-se dizer, na dinâmica mesma das formas literárias. O raciocínio de Valéry, aqui como alhures, é afim da Economia, e 
mesmo de uma Economia Política. Compreendendo Poe "à la manière" de Baudelaire, como um antídoto contra o Romantismo, Valéry diz, no mesmo texto já citado, sobre o caráter analítico do procedimento do estadunidense:

Essa análise - e esta circunstância garante-nos seu valor - aplicase e verifica-se nitidamente também em todos os campos da produção literária. As mesmas reflexões, as mesmas distinções, as mesmas observações quantitativas, as mesmas idéias diretrizes adaptam-se igualmente às obras destinadas a agir forte $\mathrm{e}$ brutalmente sobre a sensibilidade, a conquistar o público amante de emoções fortes ou de aventuras estranhas, da mesma forma como regem os gêneros mais refinados e a organização delicada das criações do poeta. (VALÉRY, 1991, p. 26)

Estas observações querem nos convencer da presença em Poe de um controle, um domínio, um poder, enfim, do autor sobre a criação literária que nenhum estilo de época, nem mesmo o Neoclassicismo, a despeito de sua conexão com o Iluminismo, chegou a conhecer. Não se trata de uma racionalização apenas no nível do ideal ou do real, mas sobre os dois níveis, uma ação da razão, pode-se dizer, tão ampla quanto eficaz no que diz respeito à realização do produto artístico, ou melhor, da arte como produto. A eficácia dessa ação racional não se apresenta apenas no campo da literatura, na prosa e na poesia; vai além, transcende a especificidade literária e atinge a generalidade, o lado de fora da literatura, a sociedade ou, num tom mais metafísico - que me parece cabível, sem dúvida -, o mundo. Valéry aguça ainda mais, num ponto alto de sua reflexão, o problema no que ele supõe ser uma solução via Poe assim:

Dizer que essa análise é válida na ordem do conto, tanto quanto na ordem do poema, que é aplicável na construção do imaginário e do fantástico, bem como na restituição e na representação literária da verossimilhança, é dizer que ela é notável por sua generalidade. O próprio daquilo que é realmente geral é a fecundidade. Chegar ao ponto em que se domina todo o campo de uma atividade é perceber necessariamente uma grande quantidade de possíveis: domínios inexplorados, caminhos a serem traçados, terras a serem exploradas, cidades a serem edificadas, relações a serem estabelecidas, procedimentos a serem desenvolvidos. Não é, portanto, surpreendente que Poe, possuindo um método tão poderoso e seguro, tenha se transformado em um inventor de diversos gêneros, dando os primeiros e os mais impressionantes exemplos do conto científico, do poema cosmogônico moderno, do romance da instrução criminal, da introdução dos estudos psicológicos mórbidos na literatura, e que toda sua obra manifeste em cada página $\mathrm{o}$ ato de uma inteligência e de uma vontade de inteligência difíceis de serem encontradas nesse grau em qualquer outra carreira literária. (VALÉRY, 1991, p. 27) 
O procedimento analítico em Poe não resulta numa conversão da literatura em coisa especializada, criada por especialista, mas na colocação do aspecto genérico como critério de valor. Se a criação literária escapa ao específico, conformando-se como generalidade, revela-se fecunda, mais produtiva, portanto. Poe, no século do acirramento do processo de produção de bens materiais, estava em consonância com o presente, ao contrário dos românticos, voltados para o passado. O paradoxo, evidente, é que essa consonância - e o seu valor - não foi percebida nem reconhecida no mundo anglo-saxão, no lugar sociocultural do poeta. Não haveria Poe, tampouco Baudelaire, sem uma ação de mão-dupla no mundo da própria literatura, uma ação que inscreve ambos no horizonte simbolista, como Valéry nos leva a pensar nos movimentos finais do seu ensaio:

Esse grande homem estaria hoje completamente esquecido se Baudelaire não tivesse se dedicado a introduzi-lo na literatura européia. Não podemos deixar de observar aqui que a glória universal de Edgar Poe só é fraca ou contestada em seu país de origem e na Inglaterra. Esse poeta anglo-saxão é estranhamente ignorado pelos seus.

Outra observação: Baudelaire e Edgar Poe trocam valores. Um dá ao outro o que tem; e recebe o que não tem. Este entrega àquele um sistema completo de pensamentos novos e profundos. Esclarece-o, fecunda-o, determina suas opiniões sobre muitos assuntos: filosofia da composição, teoria do artificial, compreensão e condenação do moderno, importância do excepcional e de uma certa estranheza, atitude aristocrática, misticismo, gosto pela elegância e pela precisão, até política... Baudelaire está completamente impregnado, inspirado, aprofundado.

Mas em troca desses bens Baudelaire dá ao pensamento de Poe uma extensão infinita. Ele o propõe para o futuro. Essa extensão, que transforma o poeta nele mesmo, no grande verso de Mallarmé, é o ato, é a tradução, são os prefácios de Baudelaire que abrem e garantem-na ao fantasma do miserável Poe. (grifo do autor) - (VALÉRY, 1991, p. 27)

São observações que nos estimulam a compreender, em primeiro lugar, e caracterizar, em segundo lugar, uma política dos poetas que visou, no alvorecer da modernidade artístico-literária ocidental, afirmar a importância do gesto criador em escala supra-nacional, como forma de romper com uma espécie de condenação dos criadores decretada no seu espaço-natal, no seu estado-nação. À medida que esse processo não significa mera adesão da parte dos autores - de Poe e Baudelaire, no caso - a valores sociais, culturais, morais de seus respectivos países, como se uns valores fossem melhores que outros, mas uma troca de valores, pode-se falar na construção de uma terceira dimensão subjetivante na relação entre ambos como uma espécie de fim dessa política. A tradução textual é o meio visível, digamos, dessa política, que tem, obviamente, seu meio invisível, fantasmagórico, misterioso, que podemos pensar como o "símbolo" dos simbolistas, o indefinível que alarga a percepção e abre outros mundos no mundo. 
BAUDELAIRE, Charles. As flores do mal. Traduzido por Ivan Junqueira. Rio de Janeiro: Nova Fronteira, 2015.

Les fleurs du mal. Paris: Hachette, 1992.

OLIVEIRA, Anelito de. Intercessões: Cruz e Sousa e Edgard Allan Poe. IN: Revista Usp, São Paulo, Coordenadoria de Comunicação Social da Usp, jun-ago 2011, p. 164-171.

POE, Edgar Allan. The raven and other favorites poems. New York: Dover Publications, 1991.

VALÉRY, Paul. Situação do Baudelaire. In: BARBOSA. João Alexandre (Org.) Variedades. Traduzido por Maiza Martins de Siqueira. São Paulo: Iluminuras, 1991.

. Variétés. Paris: Gallimard, 1924-1945. 5 vols.

WILSON, Edmund. O castelo de Axel: um estudo da imaginação literária de 1870 a 1930. Traduzido por José Paulo Paes. São Paulo: Cultrix, 1987.

Axel's Castle: a study of the imagination literature of 1870- 1930. New York: Farrar, Straus and Giroux, 2004.

Recebido em 30/09/2017

Aceito em 22/12/2017 